\title{
A study on the victims of assaults in Matara
}

Rathnaweera RHAI

Department of Forensic Medicine, Faculty of Medicine, Karapitiya, Galle

*Corresponding author: Tel: 0094-772969060. E-mail address:ajithrathnaweera@yahoo.com

MLJSL. Vol 2. No 2. September. pp 29-32

\section{Abstract}

\section{Introduction}

About 3000 victims are referred for medico-legal examination following physical hurt to the office of the Judicial Medical Officer (JMO) -General hospital Matara, every year. They include victims of physical assault, sexual assault, accidental injuries, suspects of different crimes etc.

\section{Objective}

Routine data pertaining to victims of alleged assault were analyzed to find out the demographic distribution of victims and to describe the medico-legal aspects of injuries.

\section{Materials and Methods}

All the trauma cases (2820) referred to the JMO's office General hospital Matara, from $1^{\text {st }}$ of January 2012 to $1^{\text {st }}$ of December 2012 was analyzed.

\section{Result}

Total number of trauma cases was 2820 . Out of this $1381(48 \%)$ were due to alleged assaults. Sixty seven percent were males. There were 339 victims between $21-30$ years and 326 victims between 31-40 years. 307 assaults had taken place between $2 \mathrm{pm}$ to $6 \mathrm{pm}$ and 510 between $6 \mathrm{pm}$ to $10 \mathrm{pm}$. 1242 assailants were known to the victim. Among the known assailants, 231 were relatives. 1195 were blunt force injuries and 186 were sharp force injuries. The commonest form of injury was abrasion (666) and the commonest site of injury was face (521). Category of hurt was non grievous in 1023, grievous in 305 , endangering life in 38 and fatal in the ordinary cause of nature in 15.

\section{Conclusions}

Blunt force was the commonest form of assault (86\%). As expected, adults 21 to 50 years of age (67\%), males (67\%) were the main victims of assaults. Majority of the victims had injuries and out of that abrasion was the commonest form of injury. Most of the incidents had taken place between $2 \mathrm{pm}$ to $10 \mathrm{pm} \mathrm{(59 \% )} \mathrm{and} \mathrm{the} \mathrm{highest} \mathrm{between} 6 \mathrm{pm}$ to $10 \mathrm{pm}(36 \%)$. Majority of injuries were caused by a person known to the victim (90\%).

Key words: Assaults, Alcohol, Non grievous, known assailant 


\section{Introduction}

In law, assault is a crime that involves causing a victim to apprehend violence. The term is often confused with battery, which involves physical contact. The specific meaning of assault varies between countries, but can refer to an act that causes another to apprehend immediate and personal violence, or in the more limited sense of a threat of violence caused by an immediate show of force [1,2]. Assault in some US jurisdictions is defined more broadly still as any intentional physical contact with another person without their consent; but in the majority of the United States, and in England and Wales and all other common law jurisdictions in the world, this is defined instead as battery. Some jurisdictions have incorporated the definition of civil assault into the definition of the crime making it a criminal assault to intentionally cause another person to apprehend a harmful or offensive contact[3]. A civil assault is an assault considered as a tort and not a crime. Although the same assaultive conduct can be both a tort and a crime, civil assault isolates the legal elements that results in civil liability. In a civil assault case the assailant is liable in a civil action. The victim may be entitled to monetary damages from the assailant [3].

Assault is an increasingly common cause of injury in Sri Lanka, but there have been only few previously published studies of assault victims. This retrospective study was therefore undertaken to identify demographic and social factors, assault characteristics and injuries sustained in this population.

\section{Objective}

Routine data pertaining to victims of alleged assault were analyzed to find out the demographic distribution of victims and to describe the medico-legal aspects of injuries.

\section{Methodology}

About 3000 victims are referred for medicolegal examination following physical hurt to the JMO's office-General hospital Matara every year, and out of that majority are victims of physical assaults. All the physical assault cases referred to the JMO's office, General hospital, Matara form $1^{\text {st }}$ of January 2012 to $1^{\text {st }}$ of December 2012 were retrospectively analyzed using computer programmes SPSS and EXCEL.

\section{Results}

Total number of trauma cases was 2820. Out of this $1381(48 \%)$ were due to alleged assaults.

Most victims of assault were male (67\%) and received 1310 out of a total of 1857 injuries (70\%). Women comprised $33 \%$ of victims and received 547 injuries (30\%).

The age of the victims ranged from 3 years to 85 years. There were 339 victims between 2130 years and 326 victims between $31-40$ years (Table 01).

In both sexes there was a progressive reduction in the number of victims with increasing age. Of both male and female victims, three-quarters were unmarried.

\section{Table 01}

\begin{tabular}{|ll|}
\hline Age (years) & No \\
\hline $1-10$ & $18(1.5 \%)$ \\
\hline $11-20$ & $203(15 \%)$ \\
\hline $21-30$ & $339(25 \%)$ \\
\hline $31-40$ & $326(24 \%)$ \\
\hline $41-50$ & $264(19 \%)$ \\
\hline $51-60$ & $140(10 \%)$ \\
\hline $61-70$ & $65(4.3 \%)$ \\
\hline $71-80$ & $22(0.2 \%)$ \\
\hline $81-90$ & $04(0.01 \%)$ \\
\hline
\end{tabular}

The commonest form of injury was abrasion (666) followed by contusion (429) (Table 02). Face (521) was the commonest target followed by head (299) (Table 03) 
Table 02

\begin{tabular}{|ll|}
\hline Type of injury & No \\
\hline Abrasion & $666(48 \%)$ \\
\hline Contusion & $429(31 \%)$ \\
\hline Laceration & $263(17 \%)$ \\
\hline Cut & $188(13 \%)$ \\
\hline Stab & $15(1.0 \%)$ \\
\hline Fractures & $190(13 \%)$ \\
\hline Dislocations & $05(0.36 \%)$ \\
\hline Burns & $06(0.4 \%)$ \\
\hline Others & $95(6.8 \%)$ \\
\hline No injuries & $230(16.5 \%)$ \\
\hline
\end{tabular}

Table 03

\begin{tabular}{|ll|}
\hline Position of the body & No \\
\hline Head & $299(22 \%)$ \\
\hline Face & $521(38 \%)$ \\
\hline Chest & $308(22 \%)$ \\
\hline Abdomen & $80(6 \%)$ \\
\hline Upper limb & $555(40 \%)$ \\
\hline Lower limb & $295(21 \%)$ \\
\hline
\end{tabular}

1195 were blunt force injuries and 186 were sharp force injuries (Table 04). The majority of assaults were carried out with fists and feet alone. Nine per cent of men and $3 \%$ of women were stabbed, and other weapons were used against $29 \%$ of men and $13 \%$ of women.

Table 04

\begin{tabular}{|cl|}
\hline Weapon & No \\
\hline Blunt - Hand or feet & $669(48 \%)$ \\
\hline Club & $421(30 \%)$ \\
\hline Other & $306(22 \%)$ \\
\hline Sharp - Knife & $117(8.4 \%)$ \\
\hline Sword & $38(2.7 \%)$ \\
\hline Other & $32(1.2 \%)$ \\
\hline Burns & $06(0.4 \%)$ \\
\hline
\end{tabular}

Category of hurt was non grievous in 1023 (74\%), grievous in 305 (22\%), endangering life in $38(2.5 \%)$ and fatal in the ordinary cause of nature in 15 (1.5\%).

There was a progressive daily increase in the number of patients who were assaulted throughout the week from Monday (8\%), to Sunday (25\%). Majority of cases were reported between 6 pm to $10 \mathrm{pm}$ (510) followed by $2 \mathrm{pm}$ to $6 \mathrm{pm}$ (307).

One third of male victims and all female victims stated that they have not taken alcohol in the 6 hours prior to the assault.

Over half the patients (54\%) knew why they had been assaulted.

Men were most commonly assaulted in the street near pubs ( $40 \%$ of male victims), and women at home, where almost half of them were attacked (47\%). One-third of women were assaulted in the street.

1242 (90\%) assailants were known to the victim. Among the known assailants, 231 were relatives. Eleven victims were unable to identify the sex of their attacker. In $85 \%$ of assaults the assailant was a man, in $8 \%$ a woman, and in $2 \%$ men and women. Over $80 \%$ of male assailants were estimated to be aged between 15 and 34 years old, and a similar proportion of female assailants to be between 15 and 24 years.

Half of the cases, men were assaulted by a single assailant. $69 \%$ of women were assaulted by a single attacker, and all female domestic assaults were single handed.

\section{Discussion}

As in previous British, Scandanavian [4] and American [5] studies, the majority of victims were single young men, assailed late at night during the weekend in the vicinity of, or inside, pubs. The majority of these victims had drunk alcohol prior to the assault, and its role as a causative factor in assault is generally recognized $[3,6]$. The Bristol assault study showed good broad correlation between stated recent alcohol intake and blood ethanol levels, and although the majority of 'street assault victims' had been drinking, attention was drawn to the fact that one-third of them had not been rendered more aggressive or more prone to attack through alcohol consumption $[7,8]$.

The pattern of injuries with a preponderance of facial trauma is found in other British studies. In 
comparison with North America a much smaller proportion of British assault victims are stabbed or shot. Available data show that death very rarely results from personal violence in Britain? The physical injuries were mainly soft tissue, but represent an appreciable workload. In this study also, face remained the commonest site of assault.

Victims should be made aware that they may need to seek medical help for anxiety and depression which may follow an assault, as the symptoms of the posttraumatic stress syndrome can be protracted and disabling. Work at St. George's Hospital, London, has shown that the syndrome may affect patients more seriously after personal assault than after involvement in a major incident, such as a train crash [9].

\section{Conclusions}

Blunt force was the commonest form of assault $(86 \%)$ and the category of hurt was non grievous in $74 \%$ of cases. As expected, adults 21 to 50 years of age $(67 \%)$, males $(67 \%)$ were the main victims of assaults. Alcohol remains a major contributory factor for incidence of assaults. Majority of the victims had injuries and out of that abrasion was the commonest form of injury. Women were most commonly punched and kicked and received proportionately more wide spread injuries than men. Most of the incidents had taken place between $2 \mathrm{pm}$ to $10 \mathrm{pm}$ (59\%) and the highest between $6 \mathrm{pm}$ to $10 \mathrm{pm}$ (36\%). Majority of injuries were caused by a person known to the victim (90\%).

\section{References}

1. Arkansas Code, Title 5, Chapter 13, Subchapter 2, \& 205-207

2. California Penal Code, Part 1, Chapter $9, \S$ 240

3. Bute S. (1988) Letter: The Roots of Violence. British Medical journal 298, 46-7.

4. Honkanen R, Kiviluoto 0 , Nordstrom R. Victims of Assault attending Casualty Departments. Scandanavian Journal of Social Medicine 1986; 8, 63-6

5. Sumner BB, Mintz ER, Brown PL. Injuries caused by personal violence. Injury 1987; $18,258-60$.

6. HMSO (1989) Home Office Research Study 108. Drinking and Disorder: A Study of nonmetropolitan violence.

7. Norton RN, Morgan MY. Mortality from interpersonal violence in Great Britain Injury 1989; 20,131-3.

8. Shepherd JP, Scully C, Shapland M, Irish M. Leslie IJ. Assault: Characteristics of Victims attending an Inner City Hospital. Injury 1988a;19, 185-190.

9. Personal Communication. (Stevens KLH. (1989) Consultant in A\&E, St. George's Hospital, London. Personal Communication). 